\title{
Strategic Analysis on the Promotion of International Competitiveness of Chinese Cultural Industry in the Context of Global Economic Development
}

\author{
Shi Xiaolei \\ Weinan Normal University, Weinan, Shaanxi, 714000
}

Keywords: Global Economy, Cultural Industry, International Competitiveness, Analysis of Problems

\begin{abstract}
With the rapid development of China's economy, the pursuit of spiritual civilization is becomin higher and higher, which makes the cultural industry develop in the direction of leaping. It can be said that the cultural industry is the most potential sunrise industry in the twenty-first century, and gradually develops into an important pillar industry of the national economy. China boasts a long history, rich cultural resources and strong market demand, so the strong momentum of the development of cultural industry has emerged. This paper mainly expounds the connotation and characteristics of the cultural industry, analyzes the current situation of the development of China's cultural industry, and puts forward some strategies to enhance the international competitiveness of China's cultural industry, so as to provide references for the development of China's cultural industry.
\end{abstract}

\section{The Connotation of Cultural Industry}

For the current academic cultural industry concept has not yet reached a consensus, mainly because of the cultural industry has rich connotation and the characteristics of uncertainty, all scholars in the growth environment, by cultural influence is also different, so to define the concept of the cultural industry will be affected by the environment limitations. Cultural industries are also more diverse, such as entertainment and tourism, creative industry, mass culture and so on. The main contents include two aspects of core cultural products and cultural services, including cultural products including books, audio and video products, electronic publications, music and newspapers and magazines and so on; and cultural services provide for-profit cultural related services, such as film services, library services, entertainment services etc. In the information age, the world economy is facing an extremely profound change. The cultural industry is attracting more and more attention. The United Nations Scientific and cultural organization puts forward that "cultural prosperity is the highest goal of development" [1-2]. Although the consumption ratio of urban and rural residents in cultural projects is significantly lower than that of developed countries, the development of economy has increased people's consumption level. Whether the social demand structure or consumption structure has changed greatly than before. People's consumption focuses on education, technology, tourism, spiritual products and so on. The development of cultural industry is an important way to meet people's growing spiritual needs, and is also an important part of building socialist spiritual civilization.

\section{Characteristics of Cultural Industry}

Different from other industries, the characteristics of cultural industry mainly reflect the following characteristics:

First of all, the cultural industry shows strong externalities. Most industries have externality more or less, but the external cultural industry is more significant, because it has broken the development of the field of economy, whether the international or domestic political political or national cultural identity, the role of cultural industries are very prominent. For a country, the cultural industry is an important part of the strategy of national culture, national culture is the basis of branch point of governance; cultural industry progress will promote the development of the 
national economy and other related industries, such as the development of the tourism industry will drive the development of transportation, catering, crafts design, retail and other industries; and the cultural industry and other industries in harmony is also very strong. Secondly, the cultural industry embodies the characteristics of high risk and high income. The production of cultural products, the circulation of investment is a high risk project, the risk mainly comes from cultural discount, namely cultural discount, the products in the international market sales culture, different countries have different cultural backgrounds, if cultural products from other countries or regions of the consumer's identity, its cultural value can not be reflected [3]. In a sense, the cultural product is a cultural expression symbol, and the birthplace of the National Geographic, there is a direct correlation, so different regions of the social system, historical background, values, aesthetic requirements for cultural products is different, which leads to the occurrence of the phenomenon of cultural discount. Of course, the high risk of general economics will bring high returns. The cultural industry is also a high return on investment industry. This is especially evident in movie investment. Finally, the cultural industry embodies the characteristics of high income elasticity. The social nature of man determines that culture is an important part in people's daily life, and the cultural industry is the market operation rules of organization system, so as to form a cultural product, pay up to a certain size of the market, this is also the basic condition of the development of the cultural industry.

\section{The Present Situation of China's Cultural Industry Development}

As China's cultural industry started late, though it has been developing for decades, compared with the developed countries, China's cultural industry is still in its infancy, and we need to explore and cultivate a mature cultural market. In particular, there are still several problems in the development of China's cultural industry.

\subsection{Lack of energy in the management system}

In China, the cultural industry has long been a category of ideology. Its development is strictly managed by the planned economy management system, which is rooted in the soil of the planned economy. Although the initial planned economic management system can play a protective role in the development of the cultural industry. But under the background of economic globalization, as in the development of the market economy, strengthen the cultural industry, the drawbacks of the planned economic system revealed beyond doubt, such as the cultural sector is not only the government, but also the cultural industry of the main business, the status quo when the players and the referee makes China's cultural market by excessive intervention; culture resources are state-owned culture units control can not play the cultural resources potential, resulting in a lot of cultural resources in China a large number of idle [4].

\subsection{The shortage of capital in the cultural industry market}

In the existing management system of our country, the government of the cultural market intervention too, hinder the social capital into the cultural field of investment; although the market economy in China reduces the cultural industry access threshold, allowing private capital and foreign capital to enter the cultural industry market, to improve the degree of diversification of cultural industry investment. But under the influence of traditional management system, China's private capital and foreign capital to enter the cultural industry market has a lot of legal or institutional barriers, and although China's accession to the WTO, but has not been fully in line with international standards, not in the international capital operation from circulation, and can absorb more international capital [5]. Leading the market of China's cultural industry shortage of funds. Lack of funds led to the scientific and technological content of China's cultural products and cultural products is relatively low, at this stage is still dominated by traditional technology, lack of innovation ability, the introduction of new and high technology and advanced equipment is still far insufficient, both product quality and technical content are lack of competitiveness, the economic benefit is not obvious. 


\subsection{Low development and utilization of cultural resources}

The development and utilization of cultural resources in China is very low, and the development and application of cultural heritage and cultural resources of the conversion rate of the product are at relatively low levels, and even some local governments in order to enhance the level of local economic development, promoting employment, local attractions development and management rights transfer to private capital or foreign capital, but not on the strict supervision and the necessary constraints, leading to business attraction unit operations are not standardized in order to quickly recover the investment, resulting in the destruction of the natural landscape or the humanities landscape [6]. Moreover, due to the lack of protection of traditional cultural resources and natural heritage resources, the loss of traditional cultural resources in China is serious, which are not conducive to the improvement of China's cultural industry's international competitiveness.

\subsection{Unbalance of regional development in cultural industry}

China has a vast region, and there are great differences in the development of regional economy, and the development of cultural industry in our country also has serious regional imbalance. For example, China's Beijing, Tianjin, Liaoning, Shandong and other Bohai areas belong to the most important place of cultural trade development. In this field, there are hundreds of key export enterprises. Jiangsu, Hubei and Hunan, Pan Yangtze River Delta region as a leader in Shanghai, the capital and technology developed, has a high degree of internationalization. Guangdong, Fujian and Guangxi have been built in the Pan Pearl River Delta region along with the establishment of China ASEAN Free Trade Area, and gradually become an important area of cultural trade between China and Southeast Asia [7]. However, compared to inland areas of China's top three regional cultural industry development is very slow, although the inland area also has a rich and unique cultural resources, but the number of key cultural export enterprises is far less than the first three, thus, there is a serious imbalance in regional development of China's cultural industry.

\section{Improving the Advantages of the International Competitiveness of China's Cultural Industry}

In view of the current situation of China's cultural industry, it is suggested that the international competitiveness of China's cultural industry should be improved from the following aspects:

\subsection{Clear the competitive advantage of cultural products}

Cultural products have both commodity attributes and cultural attributes. They are essentially different from other commodities. Compared with other countries, Chinese cultural products contain rich Chinese cultural traditions, which are their greatest strength. Since 2008, China's core cultural products and cultural services import and export volume continued to grow, and China is now the largest producer of cultural products, the total accounted for $19 \%$ of its cultural products in the global market, cultural trade market, the main products and services including cultural entertainment, culture and art supplies and facilities Sports, fitness equipment, conference and exhibition service and etc. Chinese cultural products can directly reflect the profound and profound culture of China, and the advantages of Chinese cultural products in manufacturing prices are more prominent [8]. Therefore, it is of great significance to clarify the competitive advantages of Chinese cultural products for improving our comprehensive competitiveness.

\subsection{Improving the governance structure of cultural enterprises}

Market competition is the main body of various cultural enterprises, so improving the competitiveness of cultural enterprises is also an important measure to improve the international competitiveness of China's cultural industry. The first thing is to encourage fair competition between enterprises, allowing both state-owned enterprise culture industry market, and state-owned capital holding shares of companies, but also allow private capital and foreign capital dominant form of enterprise participation, to ensure fair competition among the enterprises, follow the law of survival of the fittest market, improve the international competitiveness of enterprises. Secondly, 
the management mechanism is set up to make use of the internal competition of the enterprise. Enterprises must strictly operate according to the modern operation system and organizational structure, and achieve self-management, self-financing and self-development [9]. We should diversify the equity development, clarify the property right, establishing responsibility system, effective incentive mechanism and restraint mechanism.

\subsection{Establishing a diversified financing system}

To create a good investment and financing environment, and to provide the necessary material basis for the operation, structural adjustment and innovation of the cultural industry. The diversified investment and financing system includes investment holding, financial credit, capital financing, and the establishment of development fund and so on. The relaxation of market access system, encourage cultural enterprises, individuals and foreign capital into the market of domestic cultural industry, investment mechanism of sole proprietorship, joint venture and cooperation, joint venture and other ways to form multiple channels; credit culture industry will be included in the scope of credit, the scheme of credit policy, the construction of cultural facilities, the implementation of low interest, interest free discount and other preferential policies, to make up for the lack of financial capital; loan policy of mortgage assets. In the direct financing by issuing stocks and bonds, to raise funds through the stock market; the establishment of the cultural industry is a special development fund or guarantee fund in the fund, attract private investment, for the construction of cultural industry project discount or subsidies, to support the development of cultural industry and enterprise [10].

\subsection{Improving the demand of cultural industry}

First of all, we should give priority to the cultural industry with broad market prospects. When formulating the development strategy of cultural industry, we should choose projects with broad potential consumer groups, especially emerging industries, such as movie and TV, online games, comics, music, exhibition industry, etc., which can be strongly supported. Secondly, change the concept of national consumption and improve the maturity of cultural consumers. In the whole society to create a conducive to the development of the entertainment industry environment, so that consumers think entertainment is helpful to create a healthy social atmosphere; strengthen the protection of creative writers and artists, to create a more relaxed environment for the development for it; the correct guidance of consumers and social public opinion, in order to improve the maturity of consumer culture. Finally, to strengthen the construction of supporting service system, the development of various brokerage organization, in the cultural consumption of the role into full play; the cultural market segments, to adapt to different cultural consumption demand; hierarchical management of cultural products; to increase efforts to combat IPR infringing behavior, maintain the cultural product creator and making the legitimate rights and interests.

\section{References}

[1] Xin Z. Research on the Evaluation and the Promotion Strategy of Services Competitiveness[C]// Management and Service Science (MASS), 2011 International Conference on. IEEE, 2011:1 - 4.

[2] Paraušić V, Cvijanović D, Mihailović B, et al. Correlation between the state of cluster development and national competitiveness in the Global Competitiveness Report of the World Economic Forum 2012-2013[J]. Economic Research-Ekonomska Istraživanja, 2014, 27(1): 662-672.

[3] Xiao H. A Brief Analysis of Financial Support to Chinese Cultural Industry Development [J]. Journal of Mathematical Finance, 2017, 07(1):180-187.

[4] Han L. Study on the development situation of Chinese cultural industry cluster[C]// International Conference on Industrial Economics System and Industrial Security Engineering. IEEE, 2016:1-3.

[5] Katane I. THE MODEL OF SUPPORT AND PROMOTION SYSTEM FOR DEVELOPMENT 
OF THE STAFF COMPETITIVENESS IN MODERN ENTERPRISE AS LEARNING ORGANIZATION [J]. 2015, 2:95.

[6] Jianhua. Chinese Cultural Industry Highlights Belt-patterned Development in the 13th Five Year Plan [J]. Chinese and Foreign Cultural Exchanges: English Version, 2016(1):11-12.

[7] Jinfei. Chinese Resource-Based Cities Industry Competitiveness Evaluation and Promotion Strategy Research --To Yulin City as an Example [J]. International Journal of Technology Management, 2013:57-60.

[8] Sun Y. Analysis of the Impact of the Flow of Migrant Workers on Regional Economy: Based on the Thought about the Promotion of Jiangxi Regional Economic Competitiveness [J]. 2016, $1(1$ (43)).

[9] Vu H T, Pham L C. A dynamic approach to assess international competitiveness of Vietnam's garment and textile industry [J]. Springerplus, 2016, 5(1):1-13.

[10] Remeikiene R, Gaspareniene L. Evaluation of the Impact of the EU Structural Support on the Competitiveness of Lithuanian Economics [J]. Central European Journal of Public Policy, 2016, 14(1):74-88. 